\title{
EXPERIMENTAL AND THEORETICAL STUDY OF STABLE PHOSPHORUS YLIDES DERIVED FROM INDAZOLE IN THE PRESENCE OF DIFFERENT DIALKYL ACETYELENEDICARBOXYLATES: FURTHER INSIGHTS INTO THE REACTION MECHANISM
}

\author{
MOHAMMAD ZAKARIANEZHAD 1 1, BATOUL MAKIABADI AND MOTAHARE SHOOL ${ }^{1}$ \\ ${ }^{\prime}$ Department of Chemistry, Payam Noor University, Tehran, Iran \\ ${ }^{2}$ Department of Chemical Engineering, Sirjan University of Technology, Sirjan, Iran
}

\begin{abstract}
In the recent work, kinetics studies were made of the reactions between triphenylphosphine 1, dialkyl acetylenedicarboxylates $\mathbf{2}$ in the presence of NH-acid, such as indazole 3 . The kinetic parameters of all reactions determined by UV spectrophotometry. The second order fits were drawn and the values of the second order rate constant $(k)$ were calculated using standard equations. All reactions repeated at different solvents and temperatures. Furthermore, useful information was obtained from studies of the effect of solvent, the structure of the reactants (dialkyl acetylenedicarboxylates) and also the concentration of reactants on the reaction rates. Theoretical studies were performed for evaluation of potential energy surfaces of all structures participated in the reaction mechanism. The first step of all reactions was recognized as a rate-determining step in the reaction mechanism, on the basis of experimental and theoretical data. Theoretical studies performed for evaluation of potential energy surfaces of all structures participated in the reaction mechanism. Quantum mechanical calculations were clarified that how the ylides exist, in solution, as a mixture of two geometrical $Z$ - and $E$-isomers as a minor or major form.
\end{abstract}

Keywords: NH-acid; Kinetic investigation; Theoretical study; Z- and E-rotamers; Indazole; Triphenylphosphine

\section{INTRODUCTION}

Organophosphorus compounds have emerged as important reagents and intermediates in organic synthesis [1]. An important group of this class is phosphorus ylides, which have been used in many reactions and synthesis of organic compounds [2-11]. The prominent role of these compounds is to convert the carbonyl groups to carbon-carbon double bonds [12] from the large number of methods available for the synthesis of phosphorus ylides, the most important involve the reaction of a phosphonium salt with a base $[13,14]$. In recent years a method has been developed for the preparation of this family by using a novel approach employing vinyl phosphonium salts $[15,16]$. The phosphonium salts are most often converted to the ylides by treatment with a strong base, though weaker bases can be used if the salt is acidic enough. Michael addition of phosphorus compounds such as triphenylphosphine to acetylenic esters leads to reactive 1,3-dipolar intermediate betaines which are not detected even at low temperature [17]. These unstable species can be trapped by a protic reagent, $\mathrm{N}-\mathrm{H}$, such as methanol, amide, imide, etc. to produce various compounds e.g. ylides $[5,11]$. These ylides usually exist as a mixture of the two geometrical isomers, although some ylides exhibit one geometrical isomer. Assignment of the stability of the two $Z$ - and $E$-isomers is impossible in phosphorus ylides by experimental methods such as ${ }^{1} \mathrm{H}$ and ${ }^{13} \mathrm{C}$ NMR and IR spectroscopies, mass spectrometry and elemental analysis data. For this reason quantum mechanical calculation has been performed in order to gain a better understanding of the most important geometrical parameters and investigate how these isomers can exist in two different $E$ - and $Z$-forms. A facile synthesis of the reaction between triphenylphosphine 1, dialkyl acetylendicarboxylates $\mathbf{2}$ and indazole 3 (as a NH- heterocyclic compound) for generation of phosphorus ylides 4a-c has been earlier reported [18] (Fig. 1).

\section{Materials and Methods}

Dialkyl acetylenedicarboxilate, triphenylphosphine and indazole were purchased from Fulka (Buchs, Switzerland) and used without further purification. All extra pure solvents including the 1,2-dichloroethane and acetone also obtained from Merk (Darmstadt, Germany). A Cary UV/Vis spectrophotometer model Bio-300 was employed throughout the current work. All Geometrical structures were optimized at B3LYP/6-311++G(d,p) level of theory using Gaussian 09 and Gamess suite software package $[19,20]$. The corresponding frequencies of the structures were estimated at the same level of theory to check the stationary points without imaginary frequencies and the transition states with only one imaginary frequency. Also, the intrinsic reaction coordinate (IRC) approach [21,22] was performed to ensure that the given transition state connects with the corresponding reactants and products. (a)

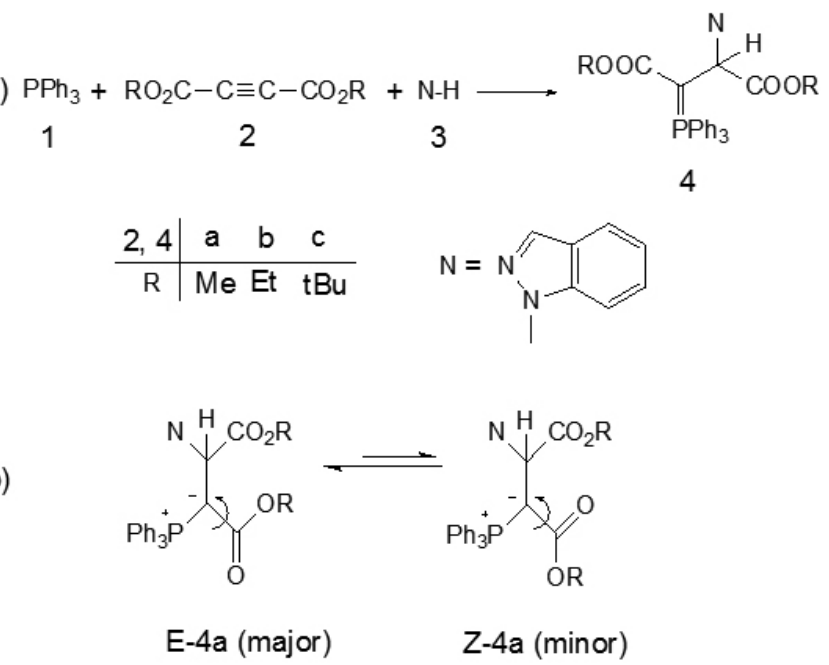

Fig. 1 (a) The reaction between triphenylphosphine 1, dialkyl acetylenedicarboxylate $\mathbf{2}$ (2a, $2 \mathbf{b}$ or $\mathbf{2 c}$ ) and indazole $\mathbf{3}$ for generation of stable phosphorus ylides $4(\mathbf{4 a}, \mathbf{4 b}$ or $4 \mathbf{c})$. (b) The two rotamers $E-\mathbf{4 a}$ and $Z-4 \mathbf{a}$ of ylide 4 a.

\section{RESULTS AND DISCUSSION}

Kinetics studies

To find the appropriate wavelength to follow the kinetic study of the reaction, the UV spectra of $3 \times 10^{-3} \mathrm{M}$ solution of compounds $1,2 \mathrm{c}$ and 3 was recorded over the wavelength range 190-400 nm. Fig.s 2, 3 and $\mathbf{4}$ show the UV spectra of compounds $\mathbf{1}, \mathbf{2} \mathbf{c}$ and $\mathbf{3}$ respectively. Then, the spectra were recorded every $10 \mathrm{~min}$ over the whole reaction time at ambient temperature (Fig. 5). From this, the appropriate wavelength was found to be $330 \mathrm{~nm}$ (corresponding mainly to triphenylphosphine 1). At this wavelength, compounds $\mathbf{1}, \mathbf{2}$ and 3 have little absorbance. This then provided the opportunity to fully investigate the kinetics of the reaction between triphenylphosphine 1, di-tert-butyl acetylenedicarboxylate $\mathbf{2 c}$ and indazole $\mathbf{3}$. 


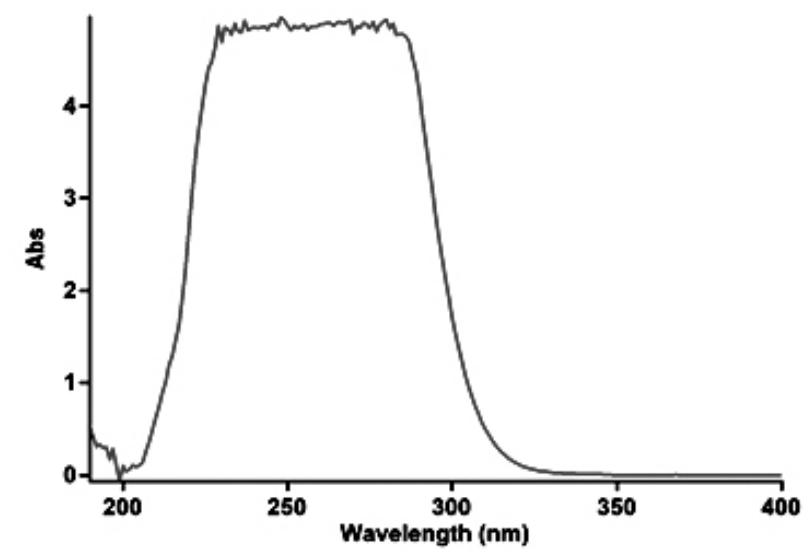

Fig. 2 The UV spectrum of $10^{-3} \mathrm{M}$ triphenyphosphine 1 in 1,2-dichloroethane.

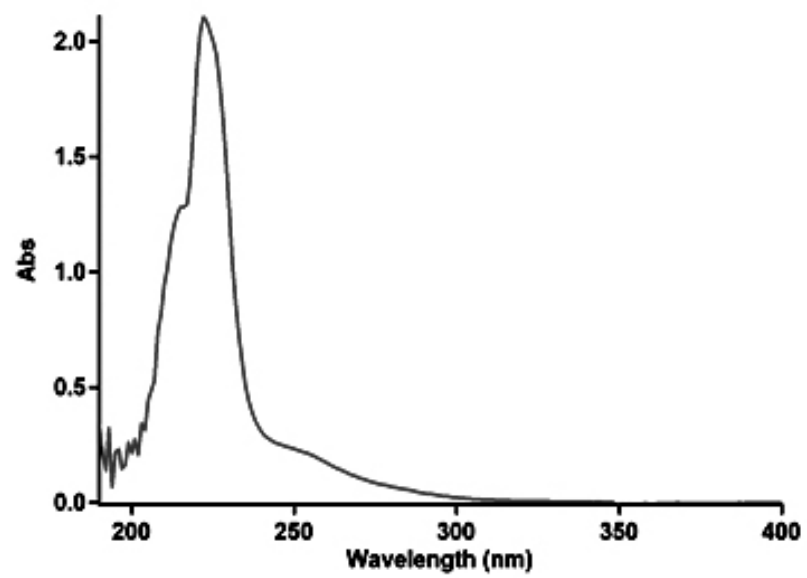

Fig. 3 The UV spectrum of $10^{-3} \mathrm{M}$ di-tert-butyl acetylenedicarboxylate $2 \mathrm{c}$ in 1,2-dichloroethane.

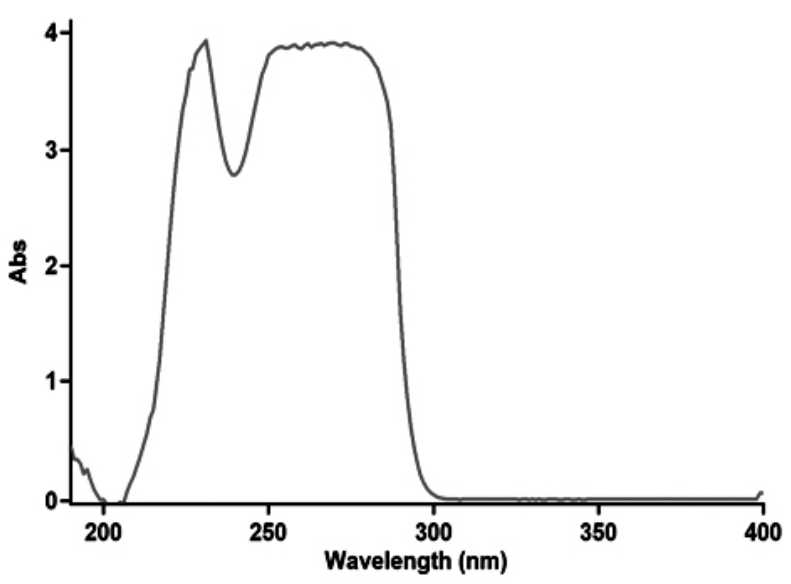

Fig. 4 The UV spectrum of $10^{-3} \mathrm{M}$ indazole 3 in 1,2-dichloroethane.

The reaction kinetics was followed by plotting UV absorbance against time at $10.0^{\circ} \mathrm{C}$. Fig. 6 shows the absorbance change (dotted line) versus time for the 1:1:1 addition reaction between compounds $\mathbf{1}, \mathbf{2} \mathbf{c}$ and $\mathbf{3}$ at $10.0^{\circ} \mathrm{C}$. The infinity absorbance (A ) that is the absorbance at the reaction completion, was obtained from Fig. 6 at $\mathrm{t}=147 \mathrm{~min}$. With respect to this value, zero, first or second curve fitting could be automatically drawn using non-linear regression analysis [23]. Using the original experimental absorbance versus time data provided a second-order fit curve (solid line) with standard deviation of 0.0021 , which provides the most satisfactory agreement with the experimental curve (dotted line) as shown in Fig. 6.

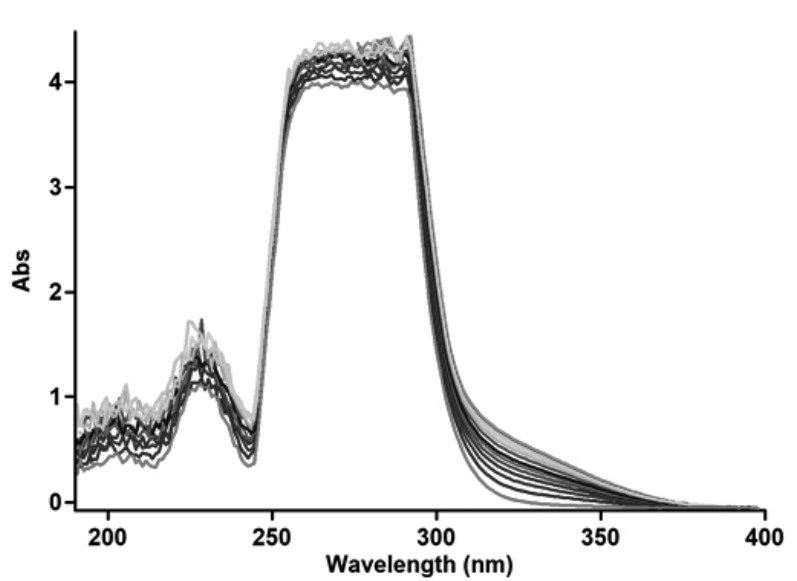

Fig. 5 The UV spectra of the reaction between $1,2 \mathrm{c}$ and $\mathbf{3}$ with $10^{-3} \mathrm{M}$ concentration of each compound as reaction proceeds in 1,2-dichloroethane.

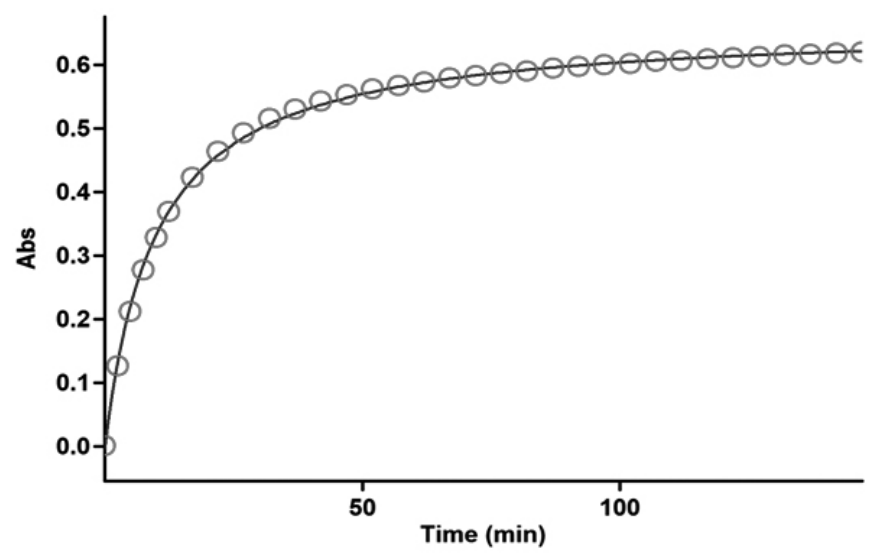

Fig. 6 Second order fit curve (solid line) accompanied by the original experimental curve (dotted line) for the reaction between compounds $\mathbf{1}, \mathbf{2 c}$ and 3 at $330 \mathrm{~nm}$ and $10.0^{\circ} \mathrm{C}$ in 1,2-dichloroethane.

Thus, the reaction between triphenylphosphine 1, di-tert-butyl acetylenedicarboxylate $\mathbf{2 c}$ and $\mathbf{3}$ follows second-order kinetics. The secondorder rate constant $(k)$ is then automatically calculated using a standard equation within the program at $10.0^{\circ} \mathrm{C}$ is reported in Table 1 . Furthermore, kinetic studies were carried out using the same concentration of each reactant in the continuation of experiments with concentrations of $5 \times 10^{-3} \mathrm{M}$ and $7 \times 10^{-3}$ $\mathrm{M}$ respectively. As expected, the second-order rate constant was independent of concentration and its value was the same as in the previous experiment. In addition, the overall order of reaction was also 2 .

\section{Effect of solvents and temperature}

To determine the effect of temperature changes and solvent environment on the rate of reaction, it was elected to perform various experiments at different temperatures and solvent polarities in the same conditions with the previous experiment. For this purpose, acetone with dielectric constant of 20.7 was chosen as a suitable solvent since it is not only could dissolved all compounds, but also did not react to them. The results show that the rate of reaction in each case was increased at higher temperatures. In addition, the rate of reaction between $\mathbf{1}, \mathbf{2 c}$ and 3 was accelerated in a higher dielectric constant environment (acetone) in comparison with a lower dielectric constant environment $(1,2$-dichloroethane $(\varepsilon=10.36))$ at all temperatures investigated. In the temperature range studied, the dependence of the second-order rate constant $(\ln k)$ of the reactions on reciprocal temperature is consistent with the Arrhenius equation, giving activation energy of reaction from the slope of this plot. 
Table 1 Values of overall second order rate constant for all reactions (1, 2c and $\mathbf{3}),(\mathbf{1}, \mathbf{2 b}$ and $\mathbf{3})$ and $(\mathbf{1}, \mathbf{2 a}$ and $\mathbf{3})$ in the presence of solvents such as 1,2-dichloroethane and acetone, respectively, at different temperatures

\begin{tabular}{|c|c|c|c|c|c|}
\hline \multirow{2}{*}{ Reaction } & \multirow{2}{*}{ Solvent } & \multicolumn{4}{|c|}{$k_{2} \cdot \mathrm{M}^{-1} \cdot \mathrm{min}^{-1}$} \\
\hline & & $10 .{ }^{\circ} \mathrm{C}$ & $15.0^{\circ} \mathrm{C}$ & $20.0^{\circ} \mathrm{C}$ & $25.0^{\circ} \mathrm{C}$ \\
\hline \multirow{2}{*}{$1,2 \mathrm{c}$ and 3} & 1,2-dichloroethane & $3.02 \times 10^{-30}$ & $5.27 \times 10^{-30}$ & $9.10 \times 10^{-30}$ & $1.80 \times 10^{-29}$ \\
\hline & acetone & $6.22 \times 10^{-30}$ & $8.61 \times 10^{-30}$ & $1.70 \times 10^{-29}$ & $2.61 \times 10^{-29}$ \\
\hline \multirow{2}{*}{$1,2 b$ and 3} & 1,2-dichloroethane & $6.45 \times 10^{-29}$ & $8.97 \times 10^{-29}$ & $1.18 \times 10^{-28}$ & $1.61 \times 10^{-28}$ \\
\hline & acetone & $8.80 \times 10^{-29}$ & $1.37 \times 10^{-28}$ & $2.18 \times 10-{ }^{28}$ & $3.02 \times 10^{-28}$ \\
\hline \multirow{2}{*}{$\mathbf{1}, \mathbf{2} \mathbf{a}$ and $\mathbf{3}$} & 1,2-dichloroethane & $6.80 \times 10^{-29}$ & $9.20 \times 10^{-29}$ & $1.30 \times 10^{-28}$ & $1.93 \times 10^{-28}$ \\
\hline & acetone & $9.20 \times 10^{-29}$ & $2.17 \times 10^{-28}$ & $3.40 \times 10^{-28}$ & $3.90 \times 10^{-28}$ \\
\hline
\end{tabular}

\section{Effect of concentration}

To determine reaction order with respect to triphenylphosphine $\mathbf{1}$ and dialkyl acetylenedicarboxylate $\mathbf{2}(\mathbf{2 c})$, in the continuation of experiments, all kinetic studies were carried out in the presence of excess $3\left(3 \times 10^{-2} \mathrm{M}\right)$. Under this condition, the rate equation may therefore be expressed as:

$$
\text { rate }=k_{o b s}[1]^{\alpha}[2]^{\beta}, k_{o b s}=k[3]^{\gamma} \text { or } \ln k_{o b s}=\ln k+\gamma \ln [3]
$$

In this condition, using the original experimental absorbance versus time data provides a second order fit curve (solid line) on the experimental curve at $330 \mathrm{~nm}$. The value of the rate constant was as same as that of obtained from the previous experiment. The same results obtained with repetition of the experiments with $5 \times 10^{-2} \mathrm{M}$ and $7 \times 10^{-2} \mathrm{M}$ of 3 obtained. In fact, the experimental data indicated that the observed pseudo second-order rate constant $\left(k_{\mathrm{obs}}\right)$ was equal to the overall second-order rate constant of the reaction. It means that $\gamma$ is zero in the equation (1). It appears that the reaction is zero with respect to 3 (NH-acid) and second order with the sum of $\mathbf{1}$ and $\mathbf{2}(\mathbf{2 c})(\alpha+\beta=2)$.

To determine the reaction order with respect to triphenylphosphine 1 , the continuation of the experiment was performed in the presence of excess $2(\mathbf{2 c})$. In this condition, the rate equation may therefore be expressed as:

$$
\text { rate }=k_{o b s}^{\prime}[1]^{\alpha}[3]^{\gamma}, k_{o b s}^{\prime}=k^{\prime}[2]^{\beta}
$$

The original experimental absorbance versus time data provides a pseudofirst-order fit curve at $330 \mathrm{~nm}$, which exactly fits the experimental curve (dotted line) as shown in Fig. 7. As a result, since $\gamma=0$ (as determined previously), it is reasonable to accept that the reaction is first order with respect to compound $\mathbf{1}(\alpha=1)$. Because the overall order of reaction is $\mathbf{2}(\alpha+\beta+\gamma=2)$, it is obvious that $\beta=1$ and the order of dialkyl acetylenedicarboxylate 2 (2c) must be equal to 1 . This observation was also obtained from reactions between $(\mathbf{1}, \mathbf{2 b}$ and $\mathbf{3})$ and $(\mathbf{1}, \mathbf{2 a}$ and $\mathbf{3})$. Based on the above results, a simplified proposed reaction mechanism is shown in Fig. 8.

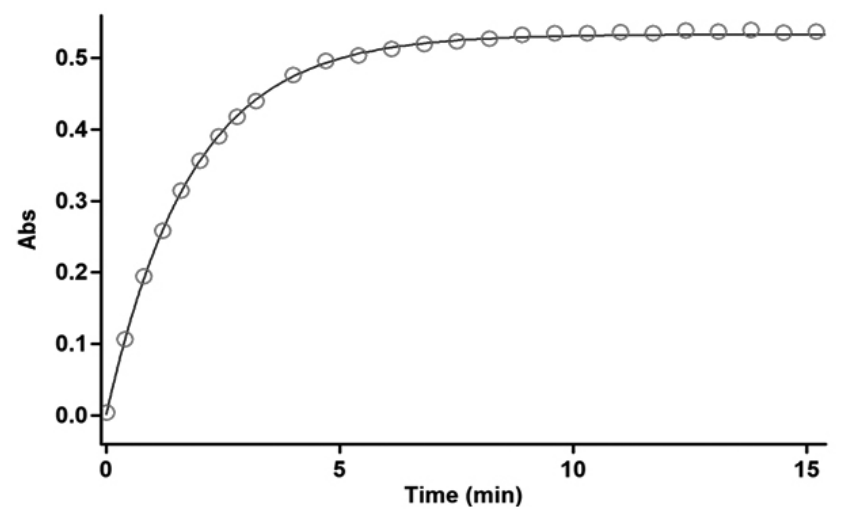

Fig. 7 Pseudo first order fit curve (solid line) for the reaction between 1 and $\mathbf{3}$ in the presence of excess $2(2 \mathrm{c})\left(10^{-2} \mathrm{M}\right)$ at $330 \mathrm{~nm}$ and $10.0^{\circ} \mathrm{C}$ in 1,2-dichloroethane.

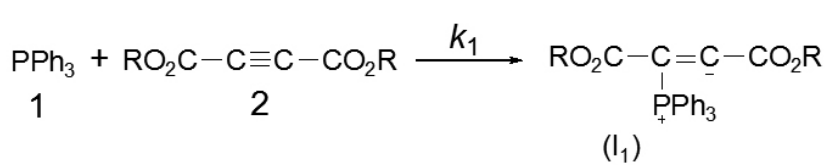

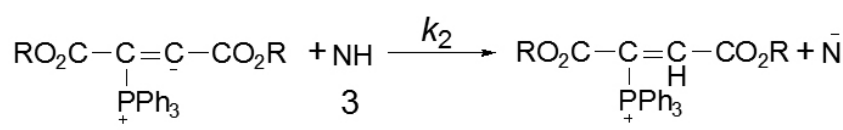

$\left(I_{1}\right)$

$\left(I_{2}\right)$

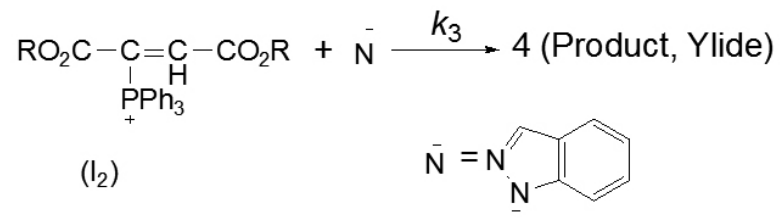

Fig. 8 Proposed mechanism for the reaction between 1, 2(2a, $2 \mathbf{b}$ or $\mathbf{2 c})$ and $\mathbf{3}$ for generation of phosphorus ylides $\mathbf{4 a - c}$.

If the first step (rate constant $k_{1}$ ) is the rate-determining step, in this case, bonding of solvent to the dispersed charge in transition state is much stronger than the reactants, with lack of charge. The solvent, thus stabilizes the transition state more than it does the reactants and speeds up the reaction. Our experimental results show that the solvent with higher dielectric constant exerts a strong effect on the rate of reaction (see Table 1). Results indicate that the first step $\left(k_{1}\right)$ of the proposed mechanism could be the rate-determining step. However, a good kinetic description of the experimental result using a mechanistic scheme based upon the steady state approximation is frequently taken as evidence of its validity. By application of this, the rate of the formation of product 4 from the reaction mechanism (Fig. 8) is given by:

$$
\frac{d[4]}{d t}=\frac{d[\text { ylide }]}{d t}=\text { rate }=k_{3}\left[I_{2}\right]\left[\mathrm{N}^{-}\right]
$$

By replacing the value of $\left[\mathrm{I}_{1}\right]$ and $\left[\mathrm{I}_{2}\right]$;

$$
\text { rate }=k_{1}[1][2]
$$

This equation is compatible with the results obtained by UV spectrophotometry. With respect to the equation (6) that shows the overall reaction rate, the activation parameters involving $\Delta \mathrm{G}^{\#}, \Delta \mathrm{S}^{\#}$ and $\Delta \mathrm{H}^{\#}$ could be now calculated for the first step (rate-determining step), as an elementary reaction, on the basis of Eyring equation. The results are reported in Table 2. 
Table 2. The activation parameters involving $\mathrm{DG}^{\#}, \mathrm{DS}^{\#}$ and $\mathrm{DH}^{\#}$ for the reactions between $(\mathbf{1}, \mathbf{2 c}$ and $\mathbf{3}),(\mathbf{1}, \mathbf{2} \mathbf{b}$ and $\mathbf{3})$ and $(\mathbf{1}, \mathbf{2 a}$ and $\mathbf{3})$ in 1,2 -dichloroethane

\begin{tabular}{|c|c|c|c|c|}
\hline Reaction & $\mathrm{Ea}^{\#} / \mathrm{kJ} \mathrm{mol}^{-1}$ & $\Delta \mathrm{G}^{\#} / \mathrm{KJ}^{-1} \mathrm{~mol}^{-1}$ & $\Delta \mathrm{H}^{\# /} \mathrm{kJ} \cdot \mathrm{mol}^{-1}$ & $\Delta \mathrm{S}^{\#} / \mathrm{J} \cdot \mathrm{mol}^{-1} \cdot \mathrm{K}^{-1}$ \\
\hline $\mathbf{1 , 2}$ and $\mathbf{3}$ & 82.77 & 117.64 & 80.35 & -128.3 \\
\hline $\mathbf{1 , 2 b}$ and $\mathbf{3}$ & 42.32 & 83.49 & 39.94 & -149.84 \\
\hline $\mathbf{1 , 2 a}$ and $\mathbf{3}$ & 48.73 & 96.46 & 46.32 & -172.51 \\
\hline
\end{tabular}

\section{Further kinetic investigations}

To confirm the above observations, further experiments were performed with diethyl acetylenedicarboxylate $\mathbf{2 b}$ and dimethyl acetylenedicarboxylate 2a, respectively, under the same conditions used in the previous experiments. The values of the second-order rate constant $(k)$ for the reactions between $(\mathbf{1}, \mathbf{2 b}$ and $\mathbf{3})$ and $(\mathbf{1}, \mathbf{2 a}$ and $\mathbf{3})$ are reported in Table $\mathbf{1}$ for all solvents and temperatures investigated. The original experimental absorbance curves (dotted line) accompanied by the second order fit curves (solid line), which exactly fit experimental curves (dotted line) confirm the previous observations. As can be seen from Tables $\mathbf{1}$ and $\mathbf{2}$, the behavior of diethyl acetylenedicarboxylate $\mathbf{2 b}$ and dimethyl acetylenedicarboxylate $\mathbf{2 a}$ is as same as the di-tert-butyl acetylenedicarboxylate 2c. The rate of the former reactions was also accelerated in a higher dielectric constant environment and with higher temperatures. It seems that both inductive and steric factors for the bulky alkyl groups in $\mathbf{2 c}$ tend to reduce the overall reaction rate (see equation $\mathbf{6}$ ). In the case of dimetyl acetylenedicarboxylate $\mathbf{2 a}$, the lower steric and inductive effects of the dimethyl groups exert a strong effect on the rate of reaction. As can be seen from Table $\mathbf{2}$, enthalpy of activation $\left(\Delta \mathrm{H}^{*}\right)$ considerably increases on going from $\mathbf{4 a}$ or $\mathbf{4} \mathbf{b}$ to 4c. Significantly negative value of the entropy of activation $\left(\Delta \mathrm{S}^{\#}\right)$ suggests that the transition state is more ordered than the starting reactants. In the presence of $\mathbf{2 a}$ and $\mathbf{2 b}$, the transition state is more ordered than that in the presence of $\mathbf{2 c}$ The more negative value of the entropy of activation $\left(\Delta \mathrm{S}^{\#}\right)$ is accompanied by a decrease in the enthalpy of activation $\left(\Delta \mathrm{H}^{\#}\right)$. Decrease in $\Delta \mathrm{S}^{\#}$ and increase in $\Delta \mathrm{H}^{\#}$ are more sizeable on going from $4 \mathbf{a}$ or $\mathbf{4 b}$ to $\mathbf{4 c}$.

\section{Theoretical Study}

\section{Energetics and geometries in gas phase}

In order to gain further insight to the reaction mechanism, all structures were optimized at B3LYP/6-311++g(d,p) level of theory. Nucleophilic attack of triphenylphosphine $\mathbf{1}$ to dimethylacetylenedicarboxylate $\mathbf{2 a}$ in different directions, leading to the formation of two intermediates I1-I and I1-II which are different in the orientation of one of COOMe group. Thus, two different reaction paths (I and II) could be predicted which initiate from I1-I and I1-II. The potential energy profiles for two pathways I and II are shown in Fig. 9. Also, the optimized geometries of all structures are included in Fig.s $\mathbf{1 0}$ and 11. As can be seen, reaction paths include two steps. As expeted, The third step of the reaction, because of the high tendency of $\mathrm{S}^{-}$for bonding to $\mathrm{C} 5$, didn't observe. Two different paths I and II leading to the different geometrical isomers, $\mathbf{P}-\boldsymbol{E}$ and $\mathbf{P}-\boldsymbol{Z}$, respectively. Comparison of the potential energy surfaces shows that all structures including intermediates and transition states (except product) in the path $\mathbf{I}$, are more stable than those of the path II. Thus, the overall reaction proceeds via two steps with barrier heights of 51.84 (67.74) and $29.55(27.42) \mathrm{kJ} / \mathrm{mol}$, respectively. The first step of the reaction with 22.29 (40.33) $\mathrm{kJ} / \mathrm{mol}$ more energy barrier than the second step, was recognized as rate-determining step.

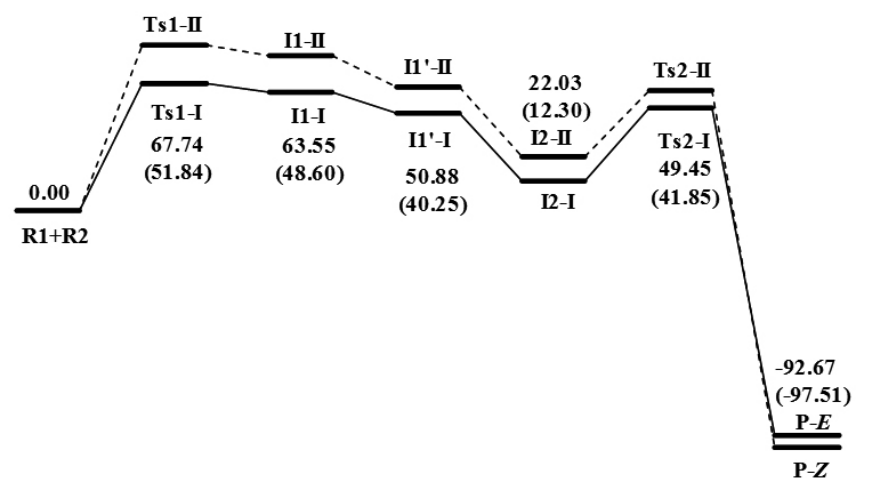

Fig. 9 Potential energy diagram (including zero point energy) along the different reaction pathways (I and II) at B3LYP/6-311++G(d,p) level of theory. Relative energies are in $\mathrm{kJ} / \mathrm{mol}$.

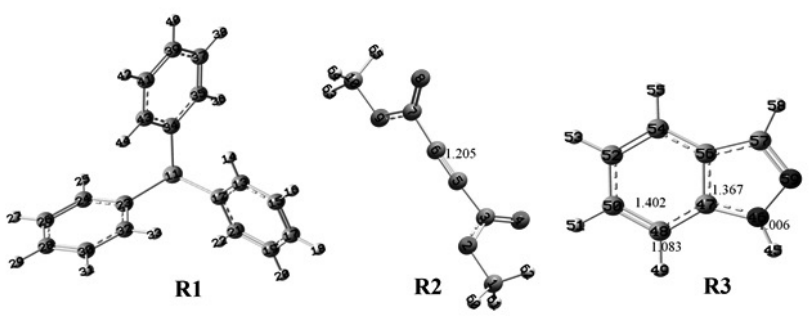

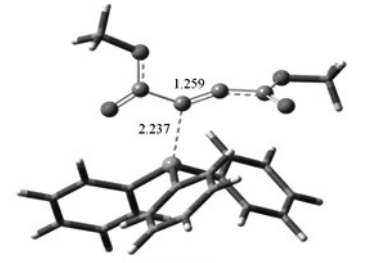

Ts1-I
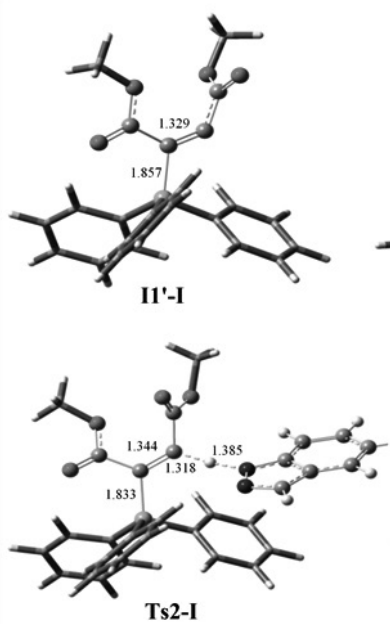

Ts2-I

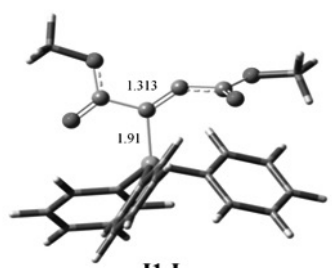

I1-I

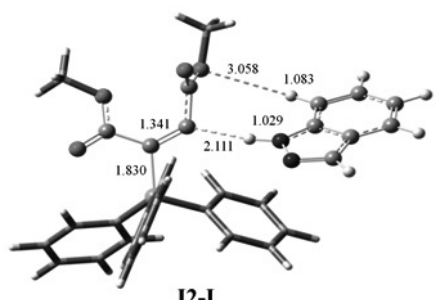

I2-I

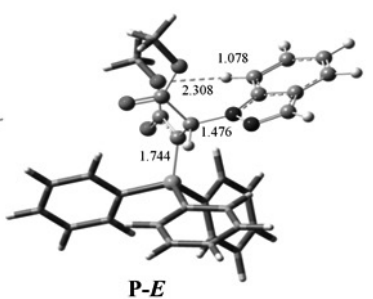

$\mathrm{P}-E$
Fig. 10 Optimized geometries of all structures (including reactants, transition states, intermediates and products) along the reaction path $\mathbf{I}$ at B3LYP/6-311++G(d,p) level of theory.

The overall reaction with relative enthalpy and relative free energy of $-94.38 \mathrm{~kJ} / \mathrm{mol}(-99.42 \mathrm{~kJ} / \mathrm{mol})$ and $27.17 \mathrm{~kJ} / \mathrm{mol}(22.91 \mathrm{~kJ} / \mathrm{mol})$ respectively is exothermic and non-spontaneous. In the synthesis of stable phosphorous ylide in the presence of indazole, P-E was recognized as major isomer [18], but, from the theoretical result, the $\mathbf{P}-\boldsymbol{E}$ is less stable than $\mathbf{P}-\boldsymbol{Z}$ by $4.84 \mathrm{~kJ} / \mathrm{mol}$. Because of the results obtained, the reaction mechanism should be investigated in more detail. The energy barrier of the first step in path $\mathbf{I}$ is less than the path II and kinetic stability was created in path I by $15.91 \mathrm{~kJ} / \mathrm{mol}$. It's obvious that the reaction proceeds on the path $\mathbf{I}$ with less barrier energy leading to the major product $(\mathbf{P}-\boldsymbol{E})$ which is less stable than $\mathbf{P}-\boldsymbol{Z}$ and is plausible to convert to $\mathbf{P}-\boldsymbol{Z}$. This process has the energy barrier of 72.89 or $76.62 \mathrm{~kJ} / \mathrm{mol}$ which is relatively high (Fig. 12) (It should be noted that two different energy barrier is related to orientation of COOMe group in two different orientations). Even if we assume that each products convert into each other, then the $\mathbf{P}-\boldsymbol{Z}$ should be the major isomer which is in contradiction with experimental results. Moreover, its plausible that the reaction path changes by $\mathbf{I} 1-\boldsymbol{Z}$ to $\mathbf{I} 1-\boldsymbol{E}$ interconvertion, in the path I goes into $\mathbf{P}-\boldsymbol{E}$, with passing from $14.31 \mathrm{~kJ} / \mathrm{mol}$ barrier height (Fig. 12). So, from the theoretical results, more kinetic priority of the path $\mathbf{I}$ than the 
path II, the high barrier of $\mathbf{P}-\boldsymbol{E}$ to $\mathbf{P}-\boldsymbol{Z}$ conversion and desirable $\mathbf{I} 1-\boldsymbol{Z}$ to $\mathbf{I} 1-\boldsymbol{E}$ conversion are the most important parameters of the stability of P-E. Anyway, beside the specific point in which both isomers can interconvert, it is clear that the observed $\boldsymbol{Z} / \boldsymbol{E}$ ratio is kinetically controlled.

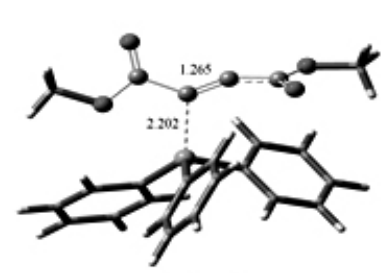

Ts1-II

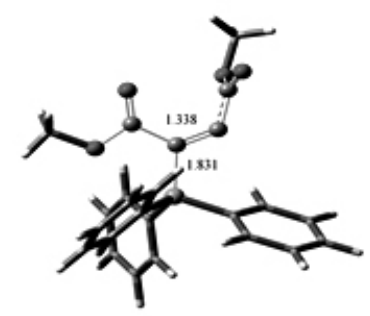

II'-II

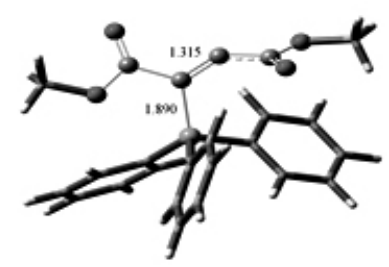

11-II

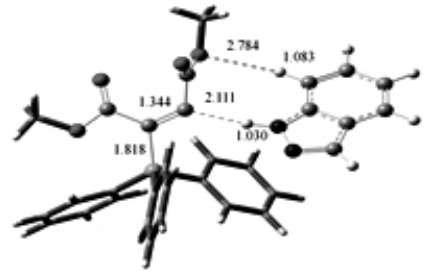

12-II

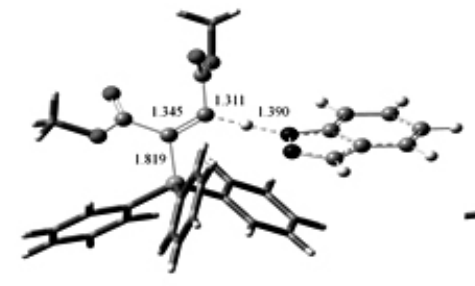

Ts2-II

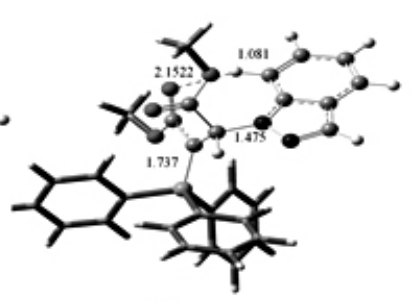

P- $Z$
Fig. 11 Optimized geometries of all structures (including transition states, intermediates and products) along the reaction path II at B3LYP/6$311++G(d, p)$ level of theory.

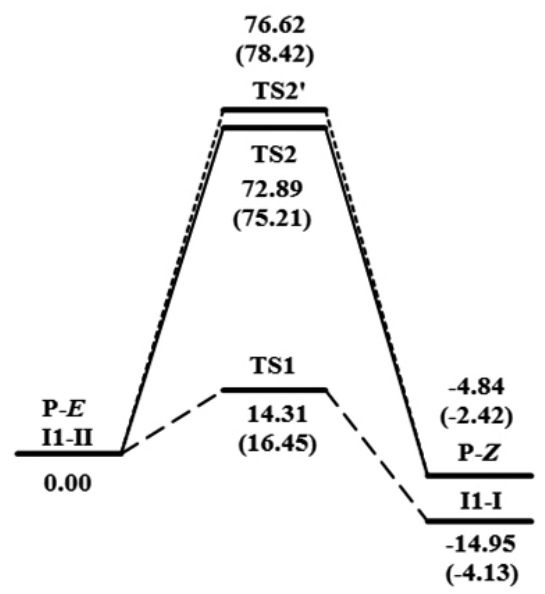

Fig. 12 Potential energy diagram ( $\mathrm{kJ} / \mathrm{mol}$ ) (including zero point energy) for conversion pathways $\left(\mathrm{P}-\mathrm{E} \rightarrow \mathrm{P}-\mathrm{Z}\right.$ and $\left.\mathrm{I}_{1}-\mathrm{II} \rightarrow \mathrm{I}_{1}-\mathrm{I}\right)$ at $\mathrm{B} 3 \mathrm{LYP} / 6-311++\mathrm{G}(\mathrm{d}, \mathrm{p})$ level of theory (data in paranthesis are in dichloromethane).

\section{Energetics and geometries in solution}

In order to check the effect of solvent on the potential energy surfaces, condensed phase calculations in 1,2-dichloroethane were carried out with polarizable continuum model (PCM) from the available experiment. The potential energy profiles for two pathways I and II in 1,2-dichloroethane are presented in Fig. 13. Compared with gas phase, the energy barrier of the first step of the path I was remained unchanged, but the energy barrier of the second step reduced by $6.71 \mathrm{~kJ} / \mathrm{mol}$. In path II, the energy barrier of the first and second steps of the reaction, respectively reduced by 8.16 and $3.58 \mathrm{~kJ} / \mathrm{mol}$ compared with the gas phase. In paths I and II, the energy barrier of the first step is considerably more than that of the second step, thus the first step of the reaction is also the rate-determining step. The path $\mathbf{I}$ is also kinetically preferable than the path II. The energy barrier of $\mathbf{P}-\boldsymbol{E}$ to $\mathbf{P}-\boldsymbol{Z}$ conversion increased to 75.21 and $78.42 \mathrm{~kJ} / \mathrm{mol}$ (Fig. 12). Also, the barrier height of the conversion of I1-Z to $\mathbf{I} 1-\boldsymbol{E}$ increased to $16.45 \mathrm{~kJ} / \mathrm{mol}$ compared with the gas phase. In addition to the kinetically preference of the path $\mathbf{I}$ to produce $\mathbf{P}-\boldsymbol{E}$, conversion of P-E to $\mathbf{P}-\boldsymbol{Z}$ needs a relatively high energy barrier. Also, through a path with less steric effect, $\mathbf{I} 1-\boldsymbol{Z}$ tend to turn into $\mathbf{I} 1-\boldsymbol{E}$ via more appropriate energy barrier. So, in spite of the thermodynamically preference of $\mathbf{P}-\boldsymbol{Z}$, the majority of $\mathbf{P}-\boldsymbol{E}$ is well established by theoretical study.

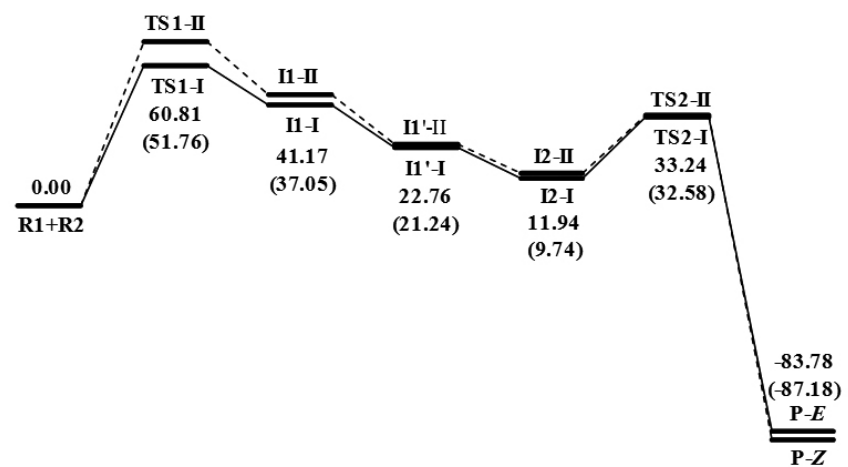

Fig. 13 Potential energy diagram (including zero point energy) along the different reaction pathways (I and II) in dichloromethane at B3LYP/6$311++\mathrm{G}(\mathrm{d}, \mathrm{p})$ level of theory. Relative energies are in $\mathrm{kJ} / \mathrm{mol}$.

\section{Reaction Rate}

According to the conventional transition state theory (CTST), the values of the rate constant $k(\mathrm{~T})$ for elementary bimolecular reactions in the gas phase are expressed by ${ }^{24}$.

$$
k=\kappa \frac{k_{B} T}{h} \frac{Q_{T S}}{Q_{R}} \exp \left[-\left(E_{T S}-E_{R}\right) / R T\right]
$$

where the $\mathrm{Q}_{\mathrm{TS}}$ and $\mathrm{Q}_{\mathrm{R}}$ are the partition functions of the transition states and the reactants, $k_{\mathrm{B}}$ is the Boltzmann constant, $\boldsymbol{\kappa}$ is the transmission coefficient. The $\mathrm{E}_{\mathrm{TS}}$ and $\mathrm{E}_{\mathrm{R}}$ are energies of the transition state and the reactants with zero point energy correction involved. The tunneling corrections were expressed as the ratio of the quantum-mechanical to classical barrier crossing rate, assuming an unsymmetrical, one-dimensional Eckart function barrier [24]. The rate constant of the first step of the reaction as overall rate constant of the reaction at $298.15 \mathrm{~K}$ in gas phase is $2.77 \times 10^{-28} \mathrm{~cm}^{3}$.molecule-1. $\mathrm{min}^{-1}$ which showing a good agreement with the experimental value $\left(1.93 \times 10^{-28} \mathrm{~cm}^{3} \cdot \mathrm{molecul}^{-1} \cdot \mathrm{min}^{-1}\right)$. By repeating the calculations in acetone (As a solvent with a high dielectric constant), the reaction rate increased to $3.51 \times 10^{-28}$ by reducing the activation energy. From the results, the exhausted energies of the reaction in the gas phase and in solution are $81.38(95.16)$ and $74.59(82.12)$ respectively. This result implies that the reaction in the path $\mathbf{I}$ is also more favorable energetically both in the gas phase and in solution.

\section{ACKNOWLEDGEMENTS}

Authors sincerely thank the Payam Noor University for providing financial support of this work.

\section{CONCLUSION}

Mechanistic investigation of the reaction between triphenylphosphine 1, dialkyl acetylenedicarboxylates $\mathbf{2}$ in the presence of $\mathrm{NH}$-acid such as indazole 3 was undertaken both experimentally and theoretically. The results can be summarized as follows: (1). The overall reaction order followed second-order kinetics with first order dependent on the concentration of triphenylphosphine 1 and dialkyl acetylenedicarboxylates 2. (2) The rates of all reactions were 
increased in solvent of higher dielectric constant and this can be related to differences in stabilization by the solvent of the reactants and the activated complex in the transition state. (3) The steric effect of bulk alkyl groups in dialkyl acetylenedicarboxylates, accompanied by the correspondingly greater inductive effect, reduced the overall reaction rate. (4) With respect to the experimental and theoretical data, the first step of the proposed mechanism $\left(k_{1}\right)$ was recognized as rate-determining step. (5) From experimental results, it was assumed that the reaction proceeds via a three step path, but, theoretical studies were demonstrated that the reaction only proceeds via two steps.(6) Despite the thermodynamically preference of $\mathbf{P}-\boldsymbol{Z}$, the majority of $\mathbf{P}-\boldsymbol{E}$ is well established by theoretical study. (7) The observed $\boldsymbol{Z} / \boldsymbol{E}$ ratio is kinetically controlled.

\section{REFERENCES}

1.- M. Crayson and E. J. Griffith, Topics in Phosphorus Chemistry, Insterscience, New York, 1972.

2.- H. R. Hudson, Primary Secondary and Tertiary Phosphines, Plyphosphines and Heterocyclic Organophosphorus (III) Compounds in the Chemistry of Organophosphorus Compounds, Wiley, New York, 1990.

3.- R. Engel, Synthesis of Carbon-phosphorus Bonds, CRC Press, Boca Rotan FL, 1988.

4.- J. Cadogan, Organophosphorus Reagents in Organic Synthesis, Academic, New York, 1979.

5.- M. Kalantari, M. R. Islami, Z. Hassani, K. Saidi, Arkivoc. x, 55, (2006).

6.- M. R. Islami, F. Mollazehi, A. Badiei, H. Sheibani, Arkivoc. xv, 25, (2005).

7.- M. T. Maghsoodlou, N. Hazeri, S. M. Habibi-Khorassani, Z. Moeeni, J. Chem. Res. 2, 566, (2006).
8.- M. Anary-Abbasinejad, H. Anaraki-Ardakani, H. Hosseini-Mehdiabad, Phosphorus Sulfur and Silicon Relat. Elem. 183, 1440, (2008).

9.- A. Hassanabadi, M. Anary-Abbasinejad, A. Dehghan, Synth. Comm. 39, $132,(2009)$.

10.- H. Anaraki-Ardakani, S. Sadeghian, F. Rastegar, A. Hassanabadi, M. Anary-Abbasinejad, Synth. Comm. 38, 1990, (2008).

11.- M. Zakarianezhad, S. M. Habibi-Khorassani, Z. Khajeali, B. Makiabadi, M. Feyzi, A. Taheri, Arkivoc. xvii, 173, (2013).

12.- B. E. Maryanoff, A. B. Reit, Chem. Rev. 89, 863, (1989).

13.- L. Fitjer, U. Quabeck, Synth. Comm. 15, 855, (1985).

14.- I. Yavari, S. Ali-Asgari, K. Porshamsian, M. Bagheri, J. Sulfur Chem. 28, 477, (2007).

15.- A. Ramazani, A. Souldozi, Phosphorus Sulfur Silicon Relat. Elem. 180, 2801, (2005).

16.- I. Yavari, A. A. Alizadeh, Monatsh Chem. 134, 435, (2003).

17.- A. Ramazani, A. Bodaghi, Tetrahedron Lett. 41, 567, (2000).

18.- M. T. Maghsoodlou, N. Hazeri, S. M. Habibi-Khorassani, R. Kakaei, M. Nassiri, Phosphorus Sulfur Silicon Relat. Elem. 181, 25, (2006).

19.- M. J. Frisch, G. W. Trucks, H. B. Schlegel, G. E. Scuseria, M. A. Robb, J. E. Peralta, et al. Gaussian, Inc, Wallingford, CT, (2009).

20.- A. A. Granovsky, PC Gamess Version 7.1.G Available at http:// classic. chem.msu.su/gran/gamess/index.html, (2009).

21.- C. Gonzalez, H. B. Schlegel, J. Phys. Chem. 94, 5523, (1990).

22.- C. Gonzalez, H. B. Schlegel, J. Chem. Phys. 90, 2154, (1989).

23.- L. M. Schwartz, R. I. Gelb, Anal. Chem. 50, 1592, (1978).

24.- C. Eckart, Phys. Rev. 35, 1303, (1980). 